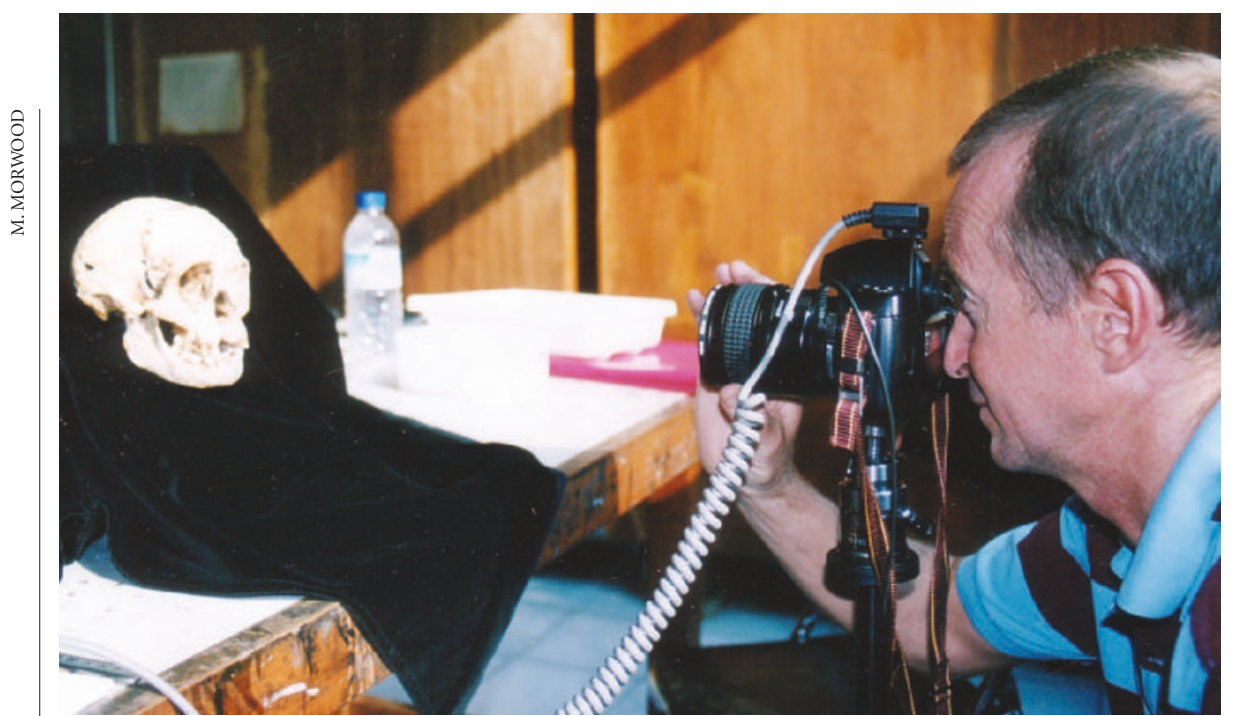

Evolution in focus: Peter Brown studies the skull of a new hominin species found in Indonesia.

\title{
Little lady of Flores forces rethink of human evolution
}

\section{Rex Dalton}

A new human-like species - a dwarfed relative who lived just 18,000 years ago in the company of pygmy elephants and giant lizards - has been discovered in Indonesia.

Skeletal remains show that the hominins, nicknamed 'hobbits' by some of their discoverers, were only one metre tall, had a brain one-third the size of that of modern humans, and lived on an isolated island long after Homo sapiens had migrated through the South Pacific region.

"My jaw dropped to my knees," says Peter Brown, one of the lead authors and a palaeoanthropologist at the University of New England in Armidale, Australia.

The find has excited researchers with its implications (see News and Views, page 1043) - if unexpected branches of humanity are still being found today, and lived so recently, then who knows what else might be out there? The species' diminutive stature indicates that humans are subject to the same evolutionary forces that made other mammals shrink to dwarf size when in genetic isolation and under ecological pressure, such as on an island with limited resources.

The new species, reported in this issue of Nature (see pages 1055 and 1087), was found by Australian and Indonesian scientists in a rock shelter called Liang Bua on the island of Flores. The team unearthed a nearcomplete skeleton, thought to be a female, including the skull, jaw and most teeth, along with bones and teeth from at least seven other individuals. In the same site they also found bones from Komodo dragons and an extinct pygmy elephant called Stegodon.

The hominin bones were not fossilized, but in a condition the team described as being like "mashed potatoes", a result of their age and the damp conditions. "The skeleton had the consistency of wet blotting paper, so a less experienced excavator might have trashed the find," says Richard Roberts of the University of Wollongong, Australia.

"Only the Indonesians were present at the actual moment of discovery - the Australian contingent had departed back to Oz," says Roberts. He credits Thomas Sutikna of the Indonesian Centre for Archaeology in Jakarta for the excellent handling of the samples. The success has inspired national pride at the centre, the researchers say. "This is very important for Indonesian society," says coauthor R.P. Soejono.

The discovery is prompting increased scrutiny of sites on other Southeast Asian islands, both to look for more of the same species and to place it in context with Homo sapiens and Homo erectus, our closest relative. Homo erectus was found to have lived on the nearby island of Java as long as 1.6 million years ago; the team suggests that the Flores hominins may be their descendants.

Dating more bones could help determine whether the species was a short-lived branch of human evolution or survived for longer. Preliminary dating places it at about 70,000 years ago, but it may extend back 800,000 years. "We were hoping we might find a little hominin from that early," says author Michael Morwood, an archaeologist at the University of New England.

In the meantime, researchers are hoping to find DNA in the bones, which would help to clarify the relationships between species. DNA has previously been extracted from European Neanderthals living in the same time period. But they have so far failed to find DNA in the teeth of the Stegodon found in the same cave, says Brown.

Additional reporting by Michael Hopkin.

www.nature.com/news/specials/flores
Novartis goes public with DNA data in bid to tackle diabetes

Jonathan Knight, San Francisco

The pharmaceutical company Novartis has entered a rare public-private partnership that will require it to place a mass of genetic data in the public domain.

The Broad Institute and Novartis Institutes for BioMedical Research, both in Cambridge, Massachusetts, announced that they have pooled resources to hunt for genes linked to adult-onset diabetes, the most common form of the disease. Novartis will contribute its diabetes research group to the project, as well as \$4.5 million over three years. The Broad Institute, headed by genome sequencer Eric Lander, will contribute its expertise in analysing genetic variation. The results are to be deposited on the Internet as they are generated, where they will be freely available. Novartis says it will share with the Broad Institute the rights to any potential drugs that emerge.

The research will investigate the genomes of several thousand Swedish diabetes patients and their families, from whom DNA samples have already been collected by Novartis and researchers at Lund University. The Broad team will search for small genetic variations that seem to correlate with the disease.

The large sample size should prove a boon to researchers. Diabetes is thought to result from a combination of genetic and environmental factors. Because researchers are looking for versions of genes that raise the risk of developing diabetes, rather than genes that definitively cause the disease, they need DNA sequences from a large number of people. "Without large patient samples, you can't distinguish signal from noise," says David Altshuler, who will direct the Broad Institute's share of the project.

It is rare for a private company to pay for a large public database. "To make it public is a good move for science, but it is unusual," says Sheldon Krimsky, a science-policy researcher at Tufts University in Medford, Massachusetts. Companies usually require a much more direct commercial benefit from such a partnership, he says.

The project is likely to generate far more data than the company can use, says Tom Hughes, head of diabetes research at Novartis Institutes. Releasing it will help the field as a whole, which in turn could lead to other commercial opportunities, he suggests. "We don't have to hold it all to ourselves to advance as a company." 